Bull. Mater. Sci., Vol. 29, No. 5, October 2006, pp. 529-534. () Indian Academy of Sciences.

\title{
Structural, optical and electrical properties of chemically deposited nonstoichiometric copper indium diselenide films
}

\author{
R H BARI, L A PATIL* and P P PATIL ${ }^{\dagger}$ \\ P.G. Department of Physics, Pratap College, Amalner 425 401, India \\ ${ }^{\dagger}$ Department of Physical Sciences, North Maharashtra University, Jalgaon 425 001, India
}

MS received 5 June 2006; revised 31 July 2006

\begin{abstract}
Thin films of copper indium diselenide (CIS) were prepared by chemical bath deposition technique onto glass substrate at temperature, $60^{\circ} \mathrm{C}$. The studies on composition, morphology, optical absorption, electrical conductivity and structure of the films were carried out and discussed. Characterization included X-ray diffraction (XRD), scanning electron microscopy (SEM), atomic force microscopy (AFM), energy dispersive $\mathrm{X}$-ray analysis (EDAX) and absorption spectroscopy. The results are discussed and interpreted.
\end{abstract}

Keywords. Copper indium diselenide; thin films; chemical bath deposition; non-stoichiometry.

\section{Introduction}

In recent years, $\mathrm{I}-\mathrm{III}-\mathrm{VI}_{2}$ ternary semiconductor compounds $(\mathrm{CuInX}, \mathrm{X}=\mathrm{S}, \mathrm{Se}, \mathrm{Te})$ have received considerable attention because of their possible application in optoelectronic devices. One of these compounds, $\mathrm{CuInSe}_{2}$, with its optical absorption coefficient exceeding $3 \times 10^{4} \mathrm{~cm}^{-1}$ at wavelengths below $1000 \mathrm{~nm}$, and its direct band gap being between 0.95 and $1.04 \mathrm{eV}$ (Hamakawa and Okamoto 1988), is an excellent solar absorber (Bloss et al 1988). Thin film polycrystalline CIS solar cells with a conversion efficiency exceeding $14 \%$ have already been achieved (Mitchell et al 1988). High absorption coefficient and low cost methods for deposition of thin films make $\mathrm{CuInSe} \mathrm{I}_{2}$ a promising material for photovoltaic devices. Thin film $\mathrm{CuIn}(\mathrm{S}, \mathrm{Se})_{2}$ cells with efficiency of $18.8 \%$ have been recorded (Nakada and Mizutani 2002). Various techniques have been employed to prepare $\mathrm{Cu}$ $\mathrm{InSe}_{2}$ thin films including flash evaporation (Elliot et al 1974; Pachori et al 1986), single source evaporation (Kazmerski et al 1976; Neumann and Nowak 1980), multiple source evaporation (Kazmerski 1979; Nealkanth et al 1984), molecular beam epitaxy (Grindle et al 1980; Mickelsen and Chen 1980), spray pyrolysis (Agnihotri et al 1983; Shirakata et al 1996), and electrodeposition (Guillemoles et al 1994; Al-Bassam 1999).

It is reported (Bhattacharya 1983; Padam 1987; Garg et al 1988; Murali 1988) that the copper indium diselenide films have been prepared by chemical bath deposition technique. Though difficult, they have successfully pre-

*Author for correspondence (lapresearch@ rediffmail.com) pared the $\mathrm{CuInSe} \mathrm{Se}_{2}$ thin films using chemical bath deposition technique. Various characterization techniques such as XRD, optical spectroscopy, scanning electron microscopy, atomic force microscopy etc were employed to study the films.

\section{Experimental}

The chemical bath deposition technique was used to deposit thin films of copper indium diselenide on glass substrate. The sources used for $\mathrm{Cu}$ and $\mathrm{In}$ as starting materials were cupric chloride $\left(\mathrm{CuCl}_{2} \cdot 2 \mathrm{H}_{2} \mathrm{O}\right.$, make-sd.fine) and indium trichloride ( $\mathrm{InCl}_{3}$, make-Lancaster). All the chemicals used were of AR grade. To obtain films of different compositions of $\mathrm{Cu}, \mathrm{In}$ and $\mathrm{Se}$, the solutions of different molarity were used. Sodium hydroxide and ammonia solution were used to adjust $\mathrm{pH}$ of the reaction mixture and to increase the film adherence. To obtain good quality films time, temperature of deposition and $\mathrm{pH}$ of the solution were optimized. The optimum time, temperature and $\mathrm{pH}$ were observed to be $2 \mathrm{~h}, 60^{\circ} \mathrm{C}$ and 10 , respectively.

The process involved the reaction of $\mathrm{Cu}^{+}$and $\mathrm{In}^{3+}$ ions with $\mathrm{Se}^{2-}$ ions in deionized water solution. Elemental selenium (99.95\%) was dissolved in aqueous solution of sodium sulphite $(\mathrm{pH}>9)$ at $90^{\circ} \mathrm{C}$ to form a $\mathrm{Na}_{2} \mathrm{SeSO}_{3}$ solution. A solution containing complex ions of indium and citrate was added to tetraamine copper. $\mathrm{Na}_{2} \mathrm{SeSO}_{3}$ solution was then added to the solution bath. In the solution, partially unstable $\mathrm{Na}_{2} \mathrm{SeSO}_{3}$ yielded $\mathrm{Se}^{2-}$ and $\mathrm{SO}_{3}{ }^{2-}$ ions. Sulphite ions reduced tetraamine copper and generated $\mathrm{Cu}^{+}$ions.

The structural properties of thin films were investigated by X-ray diffraction (XRD) using $\mathrm{CuK} \alpha(\lambda=1 \cdot 5418 \AA)$ 
Table 1. Elemental composition of CIS films.

\begin{tabular}{lccccccc}
\hline Sample no. & $\mathrm{Cu}(\mathrm{wt} \%)$ & $\mathrm{In}(\mathrm{wt} \%)$ & $\mathrm{Se}(\mathrm{wt} \%)$ & $\mathrm{Cu}(\mathrm{at} \%)$ & $\mathrm{In}(\mathrm{at} \%)$ & $\mathrm{Se}(\mathrm{at} \%)$ & $\mathrm{Cu}($ at $\%) / \mathrm{In}($ at $\%)$ \\
\hline 1 & 43.15 & 25.41 & 31.44 & 52.29 & 17.04 & 30.67 & 3.07 \\
2 & 42.37 & 15.78 & 41.84 & 49.98 & 10.30 & 39.72 & 4.85 \\
3 & 47.63 & 14.44 & 37.94 & 55.29 & 9.27 & 35.44 & 5.96 \\
4 & 56.86 & 12.11 & 31.03 & 64.22 & 7.57 & 28.21 & 8.48 \\
\hline
\end{tabular}

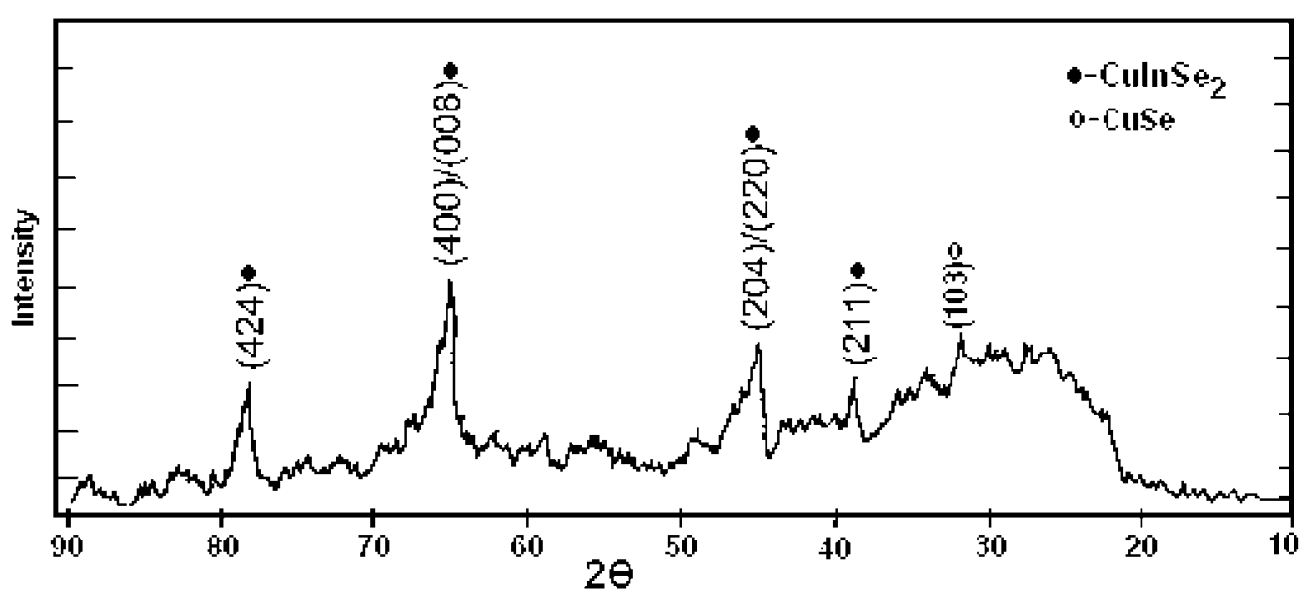

Figure 1. XRD of the sample.

radiation. The optical absorption studies of the films were carried out using Hitachi U-2000 spectrophotometer. The elemental analysis of the films was carried out using an energy dispersive spectrometer (EDS) JEOL, JED-2300, and scanning electron microscopic (SEM) studies were carried out using JEOL 6300 (LA). An AFM nanoscope (model-NSE, Serial no-245) digital instrument with a silicon nitride cantilever was used to probe different portions of the film surface in 'contact mode AFM'.

\section{Results and discussion}

\subsection{Elemental analysis by EDS}

Table 1 shows the elemental composition of the films determined by EDS.

Theoretically expected stoichiometric composition of CIS in terms of at \% is: $\mathrm{Cu}=25 \%, \mathrm{In}=25 \%, \mathrm{Se}=50 \%$.

It is clear from table 1 that the films are nonstoichiometric in nature.

\subsection{Structural analysis}

Figure 1 shows the diffractogram of sample 4 film scanned in the $2 \theta$ range of $10-90^{\circ}$. The XRD peaks approximately matched with standard ASTM data (card no. 23-209) indicating the non-stoichiometric CIS. Additional peak of $\mathrm{CuSe}$ is observed. This phase may be present due to higher $\mathrm{Cu} / \mathrm{In}$ ratio.

\subsection{SEM images representing microstructures}

Figure 2 consists of SEM images representing surface morphology of the as synthesized copper indium diselenide films with different $\mathrm{Cu} / \mathrm{In}$ ratios. The average grain sizes obtained from the SEM images are tabulated in table 2.

The grains are cubic (except in sample 4) in nature. It is clear from SEM images that the number of grains goes on increasing with the increase in $\mathrm{Cu} / \mathrm{In}$ ratio. Also, with the increase in at $\%$ of $\mathrm{Cu}$ there is a decrease in average grain size. It could be attributed to small atomic radii of $\mathrm{Cu}$ ions as compared to indium. Smaller the atomic radii, larger would be the nucleation centres and smaller would be the grains. The amount of feed material available in the reaction vessel is constant for a particular reaction. If same material would be divided on the larger nucleation centres, the grain would not grow larger but remain smaller (Sinnott 1958; Patil et al 1998; Patil and Wani 2001). This is clearly evidenced from the SEM images.

Figure 3 shows the variation of grain size with $\mathrm{Cu} / \mathrm{In}$ ratio. Grain size is found to decrease with the amount of copper in $\mathrm{CuInSe}_{2}$.

\subsection{Surface morphology}

A typical copper indium diselenide film was morphologically characterized using atomic force microscopy (AFM). Figure 4 represents AFM pictures of the film (sample 4) having $\mathrm{Cu} / \mathrm{In}$ ratio, 8.48 , which reveals the granular parti- 

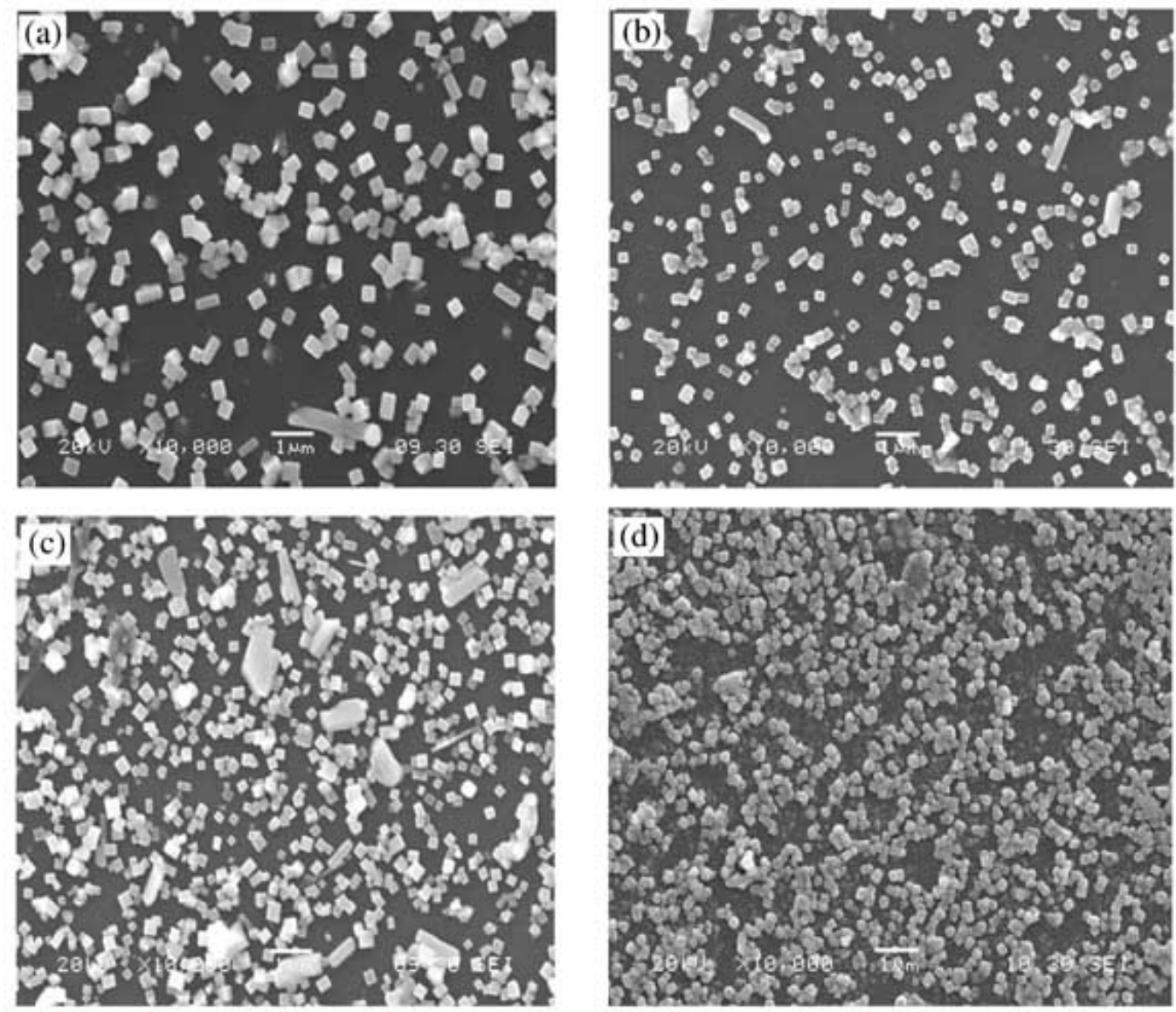

Figure 2. (a)-(d) SEM images of samples.

Table 2. Dependence of grain size on $\mathrm{Cu} / \mathrm{In}$ ratio.

\begin{tabular}{lccclcr}
\hline Sample no. & Figure 2 & $\mathrm{Cu}($ at. \%)/In (at.\%) & Grain size $(\mathrm{nm})$ & \multicolumn{2}{c}{ Nature of particles } & Shape of grains \\
\hline 1 & a & 3.07 & 354 & $\begin{array}{l}\text { Relatively small number of grains (as compared } \\
\text { to sample 2) } \\
\text { Relatively small number of grains (as compared } \\
\text { to sample 3) }\end{array}$ & Cubic \\
2 & b & 4.85 & 240 & 204 & $\begin{array}{l}\text { Relatively small number of grains (as compared } \\
\text { to sample 4) }\end{array}$ & Cubic \\
3 & c & 5.96 & 180 & Large number of grains & Spherical \\
4 & d & 8.48 & & & &
\end{tabular}

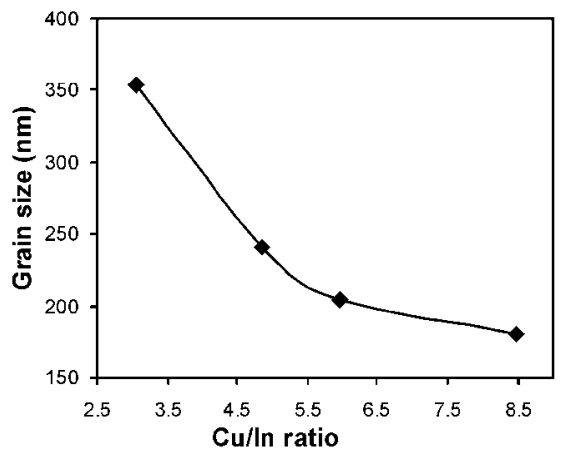

Figure 3. Variation of grain size with $\mathrm{Cu}($ at.\%)/In (at.\%) ratio. cles having spherical or elliptical nature. The spherical or elliptical grains could be attributed to faster growth due to higher concentration of copper in the composition. There was agglomeration of particles in most of the cases as evident from the $2 \mathrm{D}$ micrographs. The root mean square values of the surface roughness of the film $\left(R g_{\mathrm{AFM}}\right)$ from a number of scans from different areas of the film are calculated. It was observed that the surface roughness of the film was $10.91 \mathrm{~nm} / 1 \mu \mathrm{m} * 1 \mu \mathrm{m}$. The average grain size was observed to be $180 \mathrm{~nm}$. This observation reveals the films to be microcrystalline in nature. The average grain sizes observed from SEM and AFM images are approximately equal. 

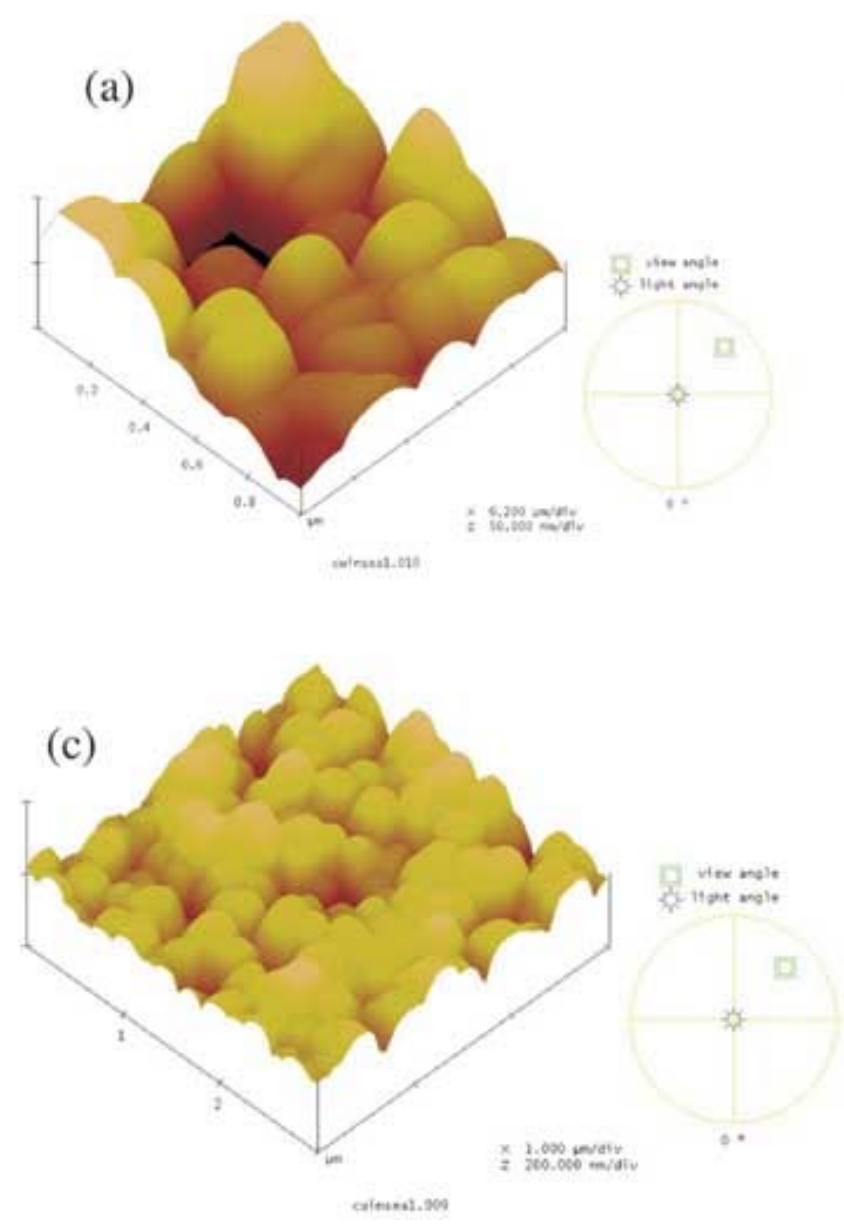

Figure 4. (a)-(d) AFM pictures of the sample.

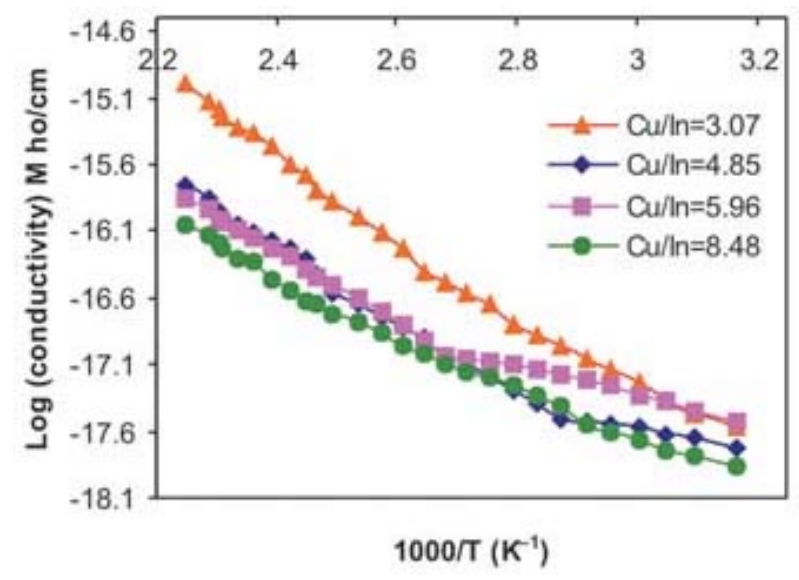

Figure 5. Variation of electrical conductivity with temperature.

\subsection{Electrical conductivity and activation energy}

Electrical conductivity of $\mathrm{CuInSe}_{2}$ thin films were measured by using d.c. two-probe method in the temperature (b)

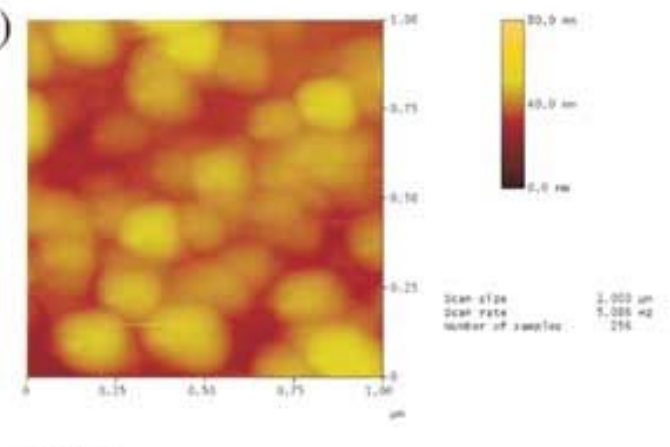

(d)

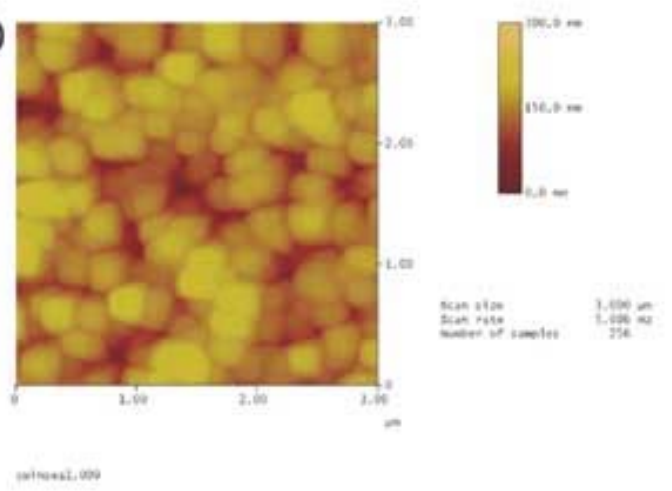

range $313-423^{\circ} \mathrm{K}$. Figure 5 shows the temperature dependence of d.c. electrical conductivity for various compositions of $\mathrm{CuInSe} \mathrm{Sn}_{2}$. The activation energies were calculated by using the slopes of the graph and are given in table 3 . It is observed that activation energy goes on decreasing with the increase in $\mathrm{Cu} / \mathrm{In}$ ratio. Lower activation energy in case of the sample having higher atomic percent of copper, could be attributed to high reactivity of copper ions with available anions. Due to high reactivity, larger at.\% of copper ions would be incorporated in the compositions, which lead to higher conductivity, and in turn, lower activation energy.

\subsection{Optical absorption studies}

Optical absorption studies of $\mathrm{CuInSe}_{2}$ films were carried out in the wavelength $(\lambda)$ range $800-1500 \mathrm{~nm}$ at room temperature. The variation of absorbance with wavelength $(\lambda)$ is shown in figure 6(a). The band gap energies of the samples were calculated from the absorption edges of the spectra. The slope drawn from the start of an absorption 
Table 3. Dependence of band gap energies and activation energy on $\mathrm{Cu} / \mathrm{In}$.

\begin{tabular}{lcccc}
\hline Sample no. & $\mathrm{Cu} / \mathrm{In}($ at.\%) & Grain size $(\mathrm{nm})$ & Activation energy $(\mathrm{eV})$ & Band energy (eV) \\
\hline 1 & 3.07 & 354 & 0.62 & 0.92 \\
2 & 4.85 & 240 & 0.55 & 1.08 \\
3 & 5.96 & 204 & 0.53 & 1.20 \\
4 & 8.48 & 180 & 0.44 & 1.30 \\
\hline
\end{tabular}
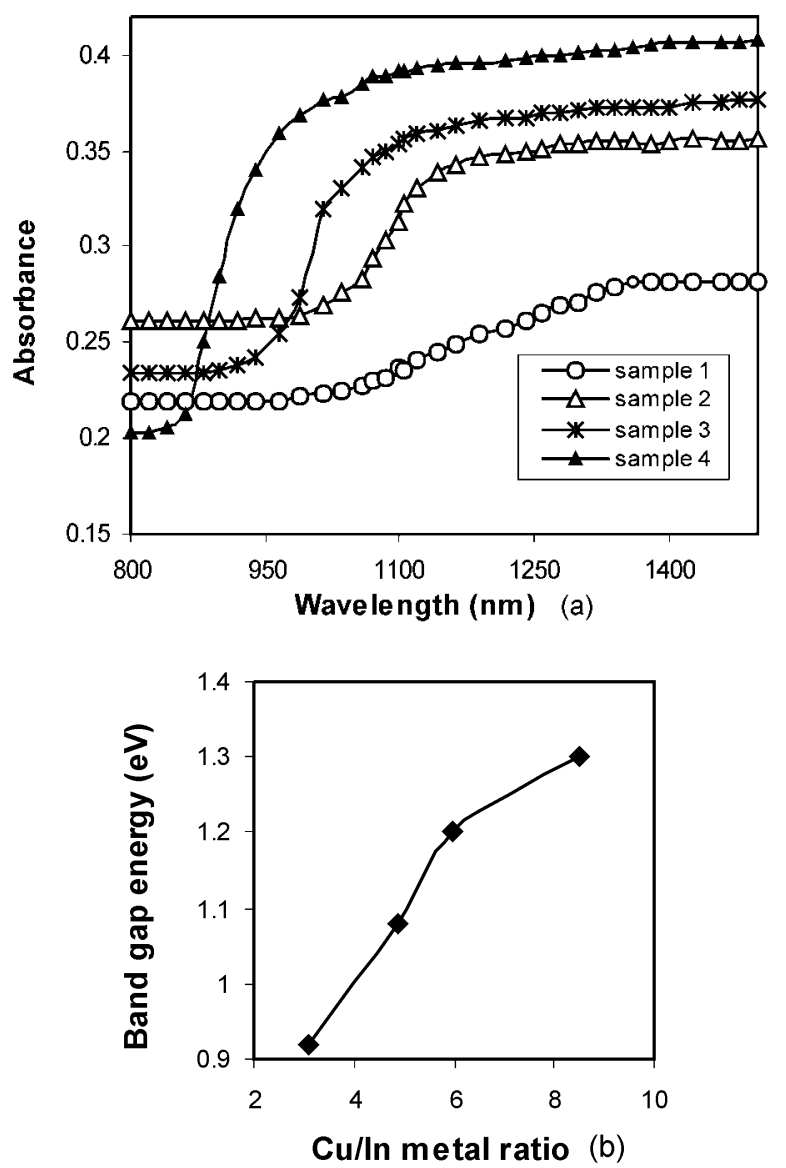

Figure 6. (a) Plot of optical absorbance vs wavelength $(\lambda)$ and (b) the variations of energy gap vs $\mathrm{Cu} / \mathrm{In}$ metal ratio.

edge (the onset of absorbance) and horizontal tangent had drawn on absorption minimum and intercepted each other at some point. The vertical line drawn from this point on wavelength axis gave the absorption edge wavelength. This value of $\lambda(\mathrm{nm})$ was then used in the following relation to know band gap energy, $E g$.

$$
E g=h v=h c / \lambda=1240 / \lambda(\mathrm{nm}) \mathrm{eV}
$$

The values of band gap energies are matching approximately with the reported band gap energy [1.04] of $\mathrm{Cu}-$
$\mathrm{InSe}_{2}$ (Wanger and Holah 1977; Horig et al 1978; Fray and Lloyd 1979).

Figure 6(b) shows the variation of optical band gap energy with $\mathrm{Cu} / \mathrm{In}$ metal ratio. It is clear from the graphs that the values of band gap energy go on increasing with the increase in $\mathrm{Cu} / \mathrm{In}$ ratio.

Table 3 summarizes the effect of at.\% of $\mathrm{Cu}$ (in CIS) on grain size, activation energy and band gap energy.

\section{Conclusions}

Copper indium diselenide films were deposited onto glass substrate by simple chemical bath deposition technique. The films obtained were uniform and had good adherence to the substrate. The EDAX of the film indicated that the films were nonstoichiometric. The values of band gap energy and numbers of grains were observed to be increasing, activation energy and grain sizes were decreasing with the increase of $\mathrm{Cu} / \mathrm{In}$ ratio.

\section{Acknowledgements}

The authors are thankful to the Head, Department of Physics and Principal, Pratap College, Amalner, for providing laboratory facilities. The authors are thankful to Dr Ajay Gupta, Centre Director, IUC, Indore, for giving consent for completing a part of this work at the consortium. One of the authors (RHB) acknowledges the University Grants Commission, Western Region, Pune, for the award of a teacher fellowship under the 10th plan.

\section{References}

Agnihotri O P, Rajaram P, Thangaraj R, Sharma A K and Raturi A 1983 Thin Solid Films 102291

Al-Bassam A A I 1999 Physica B266 192

ASTM card number 23-209

Bhattacharya R N 1983 J. Electrochem. Soc. 1302040

Bloss W H, Pfisterer F and Schock H W 1988 Adv. Solar Ener. 51

Elliot E, Tomlinson R D, Parkes J and Hampshire M J 1974 Thin Solid Films 20 S25

Fray A F and Lloyd P 1979 Thin Solid Films 5829

Garg J C, Sharma R P and Sharma K C 1988 Thin Solid Films 164269

Grindle S P, Clark A H, Falconer E, Neily M and Kazmerski L L 1980 J. Appl. Phys. 515664 
Guillemoles J F, Cowache P, Massaccesi S, Thouin L, Sanchez Lincot D and Vedel J 1994 Adv. Mater. 6379

Hamakawa Y and Okamoto H 1988 Adv. Solar Ener. 5201

Horig W, Neumann H, Scbotta H, Schumann B and Kuhn G 1978 Thin Solid Films 4867

Kazmerski L L 1979 Thin Solid Films 5829

Kazmerski L L, Ayyagari M S, Sanborn G A, White F R and Merril A J 1976 Thin Solid Films 37323

Mickelsen R A and Chen W S 1980 Appl. Phys. Lett. 365

Mitchell K, Eberspacher C, Ermer J and Pier D 1988 Proc. 20th

IEEE PV spec. conf., Las Vegas, New York, p. 1384

Murali K R 1988 Thin Solid Films 167 L19

Nakada T and Mizutani M 2002 Jpn J. Appl. Phys. 41 L165

Nealkanth G, Dhere M, Lourence C, Ramesh G, Dhere G and
Kazmerski L L 1984 Solar Cells 1359

Neumann H and Nowak E 1980 Thin Solid Films 74197

Pachori R D, Banerjee A and Chopra K L 1986 Bull. Mater. Sci. 8291

Padam G K 1987 Mater. Res. Bull. 22789

Patil L A and Wani P A 2001 Cryst. Res. Technol. 36371

Patil L A, Wani P A, Saraf K B and Wagh M S 1998 Cryst. Res. Technol. 33233

Shirakata S, Tomonori M, Kariya Tetsuya and Shigehiro I 1996 J. Appl. Phys. 351991

Sinnott M J 1958 The solid states for engineers (New York: John Wiley and Sons) pp 97-103

Wanger S and Holah G D (eds) 1977 Ternary Compounds, Inst. Phys. Conf. Ser. 35207 